\title{
Dangerfield: tobacco promotion or not?
}

Australia has some of the toughest laws prohibiting tobacco advertising in the world. ${ }^{1}$ Tobacco companies have only one legal avenue in Australia to promote their product - at the point of sale. (Under section 18 of the 1992 Tobacco Advertising Prohibition Act, exemptions may be granted by the Federal Minister of Health for events of international significance which would otherwise be lost to Australia. A recent exemption has been made in Melbourne, Australia for the Formula 1 Grand Prix race.) However, a series of advertisements, which appear to be promoting cigarettes, has recently been posted on walls around Melbourne and has been placed in a youth magazine. A close inspection of the advertisements reveals that they are actually advertising Dangerfield, a clothing company.

Dangerfield caters to avant-garde youth fashion. The advertisements have been placed on the back page of Beat, which is a free magazine targeted at the local nightclubbers (figure 1). Research has shown that the nightclubber market segment is at high risk of adopting smoking (Schofield et al, unpublished manuscript).

Winfield is currently the top-selling brand among Melbourne adults and the second most popular brand, just behind Peter Jackson, among schoolchildren. ${ }^{2}$ The Dangerfield advertising campaign blatantly copies the Rothmans "look" and advertising strategies used in Australia during the 1970s for
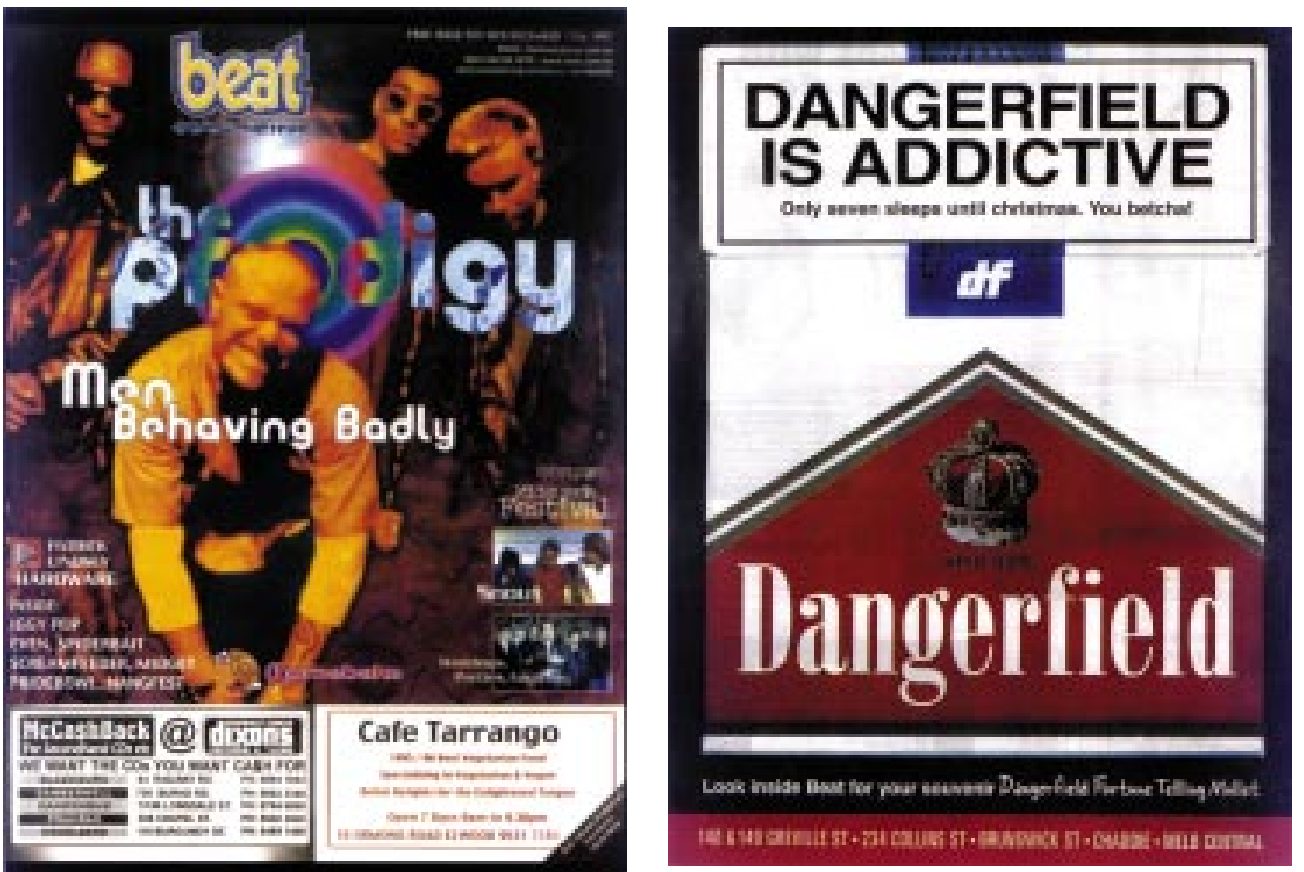

Figure 1 An advertisement for Dangerfield clothing (right) appearing on the back of "Beat" (left), a free magazine targeting local nightclubbers.

Rothmans' Winfield brand. Currently, the latest trend in the Australian nightclub scene is '70s retro fashion. Figure 2 shows one of the Dangerfield advertisements and an original Winfield advertisement. Visually, there are several parallels between the two advertisements. There is a red backdrop in both advertisements, which was traditionally used in Winfield advertisements. The slogan " ... anyhow", which heads the top of both advertisements, is a trademark of Rothmans of Pall Mall for the exclusive use of promoting Winfield. Paul Hogan, who rose to fame as an Australian comedian/actor in the early 1970s and starred in the Crocodile Dundee movies, features in both advertisements. Although the pose is different, the clothing worn by Paul Hogan is identical in the two photographs. It is almost as if the photos came from the same roll of film. The Winfield packet still looks like this today, so that even if the viewer did not know this original Winfield advertisement, the visual similarities are probably strong enough to trigger the association.

Chapman reported in Tobacco Control last year that John Cornell, an ex-manager of Paul Hogan, had publicly expressed regrets about Hogan and Cornell's involvement in Rothmans' Winfield campaign. ${ }^{3}$ Cornell claimed that when they were selling cigarettes, the health effects of smoking were unknown, despite the fact that the advertising campaign started more than 10 years after the first 

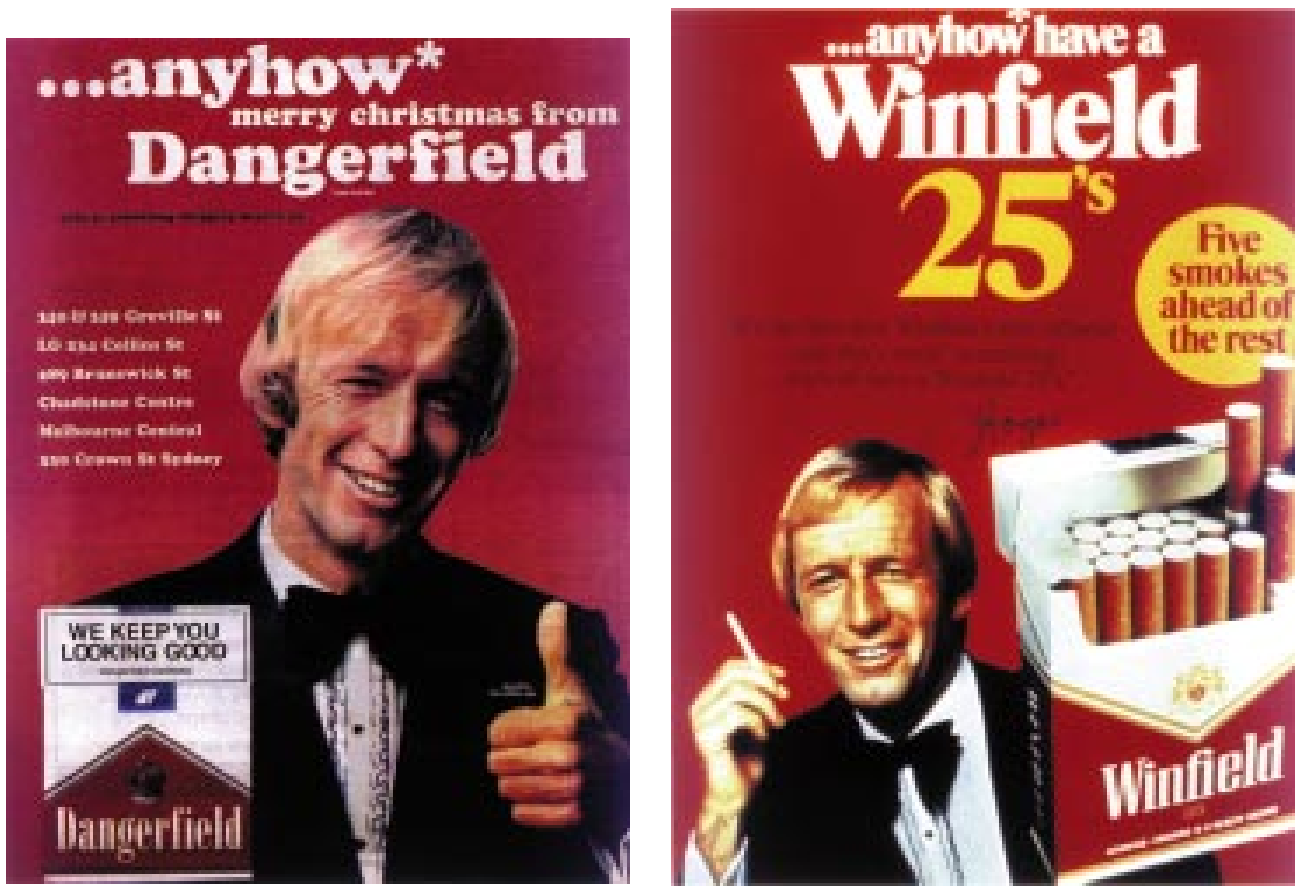

Figure 2 An advertisement for Dangerfield clothing (left) and an original ad for Winfield cigarettes (right).

reports linking smoking and lung cancer. Is it just coincidence that the Dangerfield advertisement featuring Paul Hogan was released about six months after Cornell's comments?

Figure 3 displays another Dangerfield advertisement which is dominated by a large cigarette packet. It borrows its slogan "Your international passport to P.leisure" [sic] from the Rothmans brand international advertising campaign. This advertisement also derides the strong and visible new health warning labels that were introduced in $1994^{4}$ by including the warning "maximises your root pulling power".

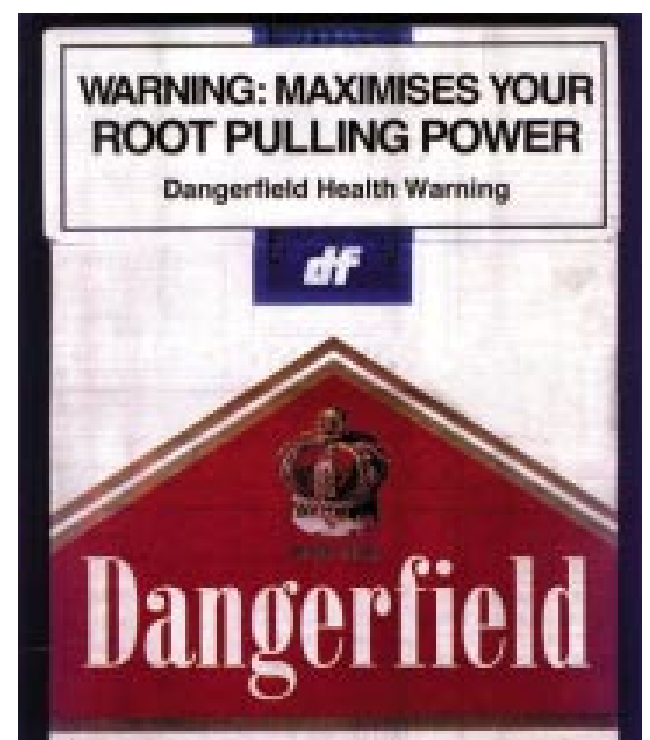

Your international passport to Pleisure

แH 1

Figure 3 An advertisement for Dangerfield associates its clothing products (or Winfield cigarettes?) with “root-pulling” power (sexual prowess).
(In Australia, "pulling a root" is a colloquial expression that means seeking and successfully obtaining sexual intercourse.) It suggests that wearing Dangerfield clothing increases a person's sexual magnetism. Or is it a "warning" label for smoking Winfield cigarettes? Fashion advertising frequently associates clothing with sexuality but what is concerning here is that this message is also being linked with tobacco products. It is not known whether there is a formal connection or agreement between Dangerfield and Rothmans. Nor is it known whether Rothmans took any steps to exercise their rights under laws governing trademarks. This would seem unlikely as the advertising promotion ran over many weeks.

Legal advice received by Quit Victoria suggests that these advertisements may well be in breach of the Tobacco Advertising Prohibition Act 1992 and the matter has been referred to the Commonwealth Department of Health. The Act "prohibits the publication, knowingly or recklessly of tobacco advertisements". "Tobacco advertisements" are defined to cover "any visual or audible message that publicises or promotes smoking". It would seem that the visual image of a Winfield packet even without a brand name is a tobacco advertisement. The inclusion of the words "knowingly or recklessly" is to prevent innocent acts from being a breach. These words imply that intention must be present for the act to be an offence. However, exemption clauses may provide Dangerfield with a promising defence to these allegations. Material that is an "accidental or incidental accompaniment to the ... publication of other material", and for which "no benefit" is received for the publication of this material, is exempt. If Dangerfield can demonstrate that the visual display of a Winfield packet was incidental to 
the advertisement of their clothing store and that Dangerfield did not receive any benefit from the use of the Winfield packet, then they are not in breach. Hence, the legal argument would revolve around the question of whether the image of a Winfield packet which constitutes the entire background of the Dangerfield advertisement is "incidental" or not.nuscript).

From a public health perspective, it would seem quite clear that this series of advertisements promotes Winfield cigarettes in addition to promoting the Dangerfield clothing company. Of even greater concern is that the promotion is targeted at young people who attend nightclubs, a group known to be at high risk of smoking (Schofield et al, unpublished manuscript).
From a legal point of view, the issue is less clear cut. Pursuing legal redress against a popular clothing company poses a dilemma for public health authorities, as launching a legal challenge may only serve to alienate the target group with which we wish to communicate. PENELOPE E SCHOFIELD Centre for Behavioural Research in Cancer, 1 Rathdowne Street, Carlton South, Victoria 3053, Australia. email:penny@accv.org.au

1 Laforge RG, Velicer WF, Levesque D, et al. Measuring support for tobacco control policy in selected areas of six countries. Tobacco Control 1998;7:241-6.

2 Winstanley M, Woodward S, Walker N. Tobacco in Australia: facts and issues, 2nd ed. Melbourne: Victorian Smoking and Health Program, 1995.

3 Chapman S. Cigarette advertisement actor cries all the way to the bank. Tobacco Control 1997;6:173-4.

4 Borland R, Hill D. The path to Australia's tobacco health warnings. Addiction 197;92:1151-7.

\section{Cigarette ads revive spirit of Joe Camel}

Mighty nasty.

The new slogan for Camel cigarettes and Camel Lights from Mezzina/Brown (advertising agency), New York, is supposed to be "Mighty tasty". And it would seem to have a rather pleasing combination of directness and playfulness - until you realise what they are up to, which, of course, is the usual.

The usual trolling for adolescents, that is.

Having taken a stab at more adult imagery, the brand that improved its market share and wrecked its industry with the infamous Joe Camel cartoon is backsliding into juvenalia with a smart-alecky campaign that trades on a Joe Camel-like dose of attitude.
One of the spreads (figure 1) shows a handsome young man running for his life from a shabby farmhouse, where the incensed, geezerish farmer is chasing him with a doublebarrel shotgun, and the young, blond farmer's daughter is in bed, sucking on a post-coital Camel. The farmer is old and dresses like Elmer Fudd. The fleeing travelling salesman is young and buff, so guess who we're supposed to be rooting for?

On one level, for the shallow and unworldly, this ad trades on the threadbare fantasy. But for extra credit it takes a self-mocking tone in discovery of its own inner cliché. A prominent "Viewer Discretion Advised" warning in the
Reprinted with permission from the 27 Fuly 1998 issue of "Advertising Age", a leading trade publication for the advertising industry. The author is a regular columnist in the magazine.-ED

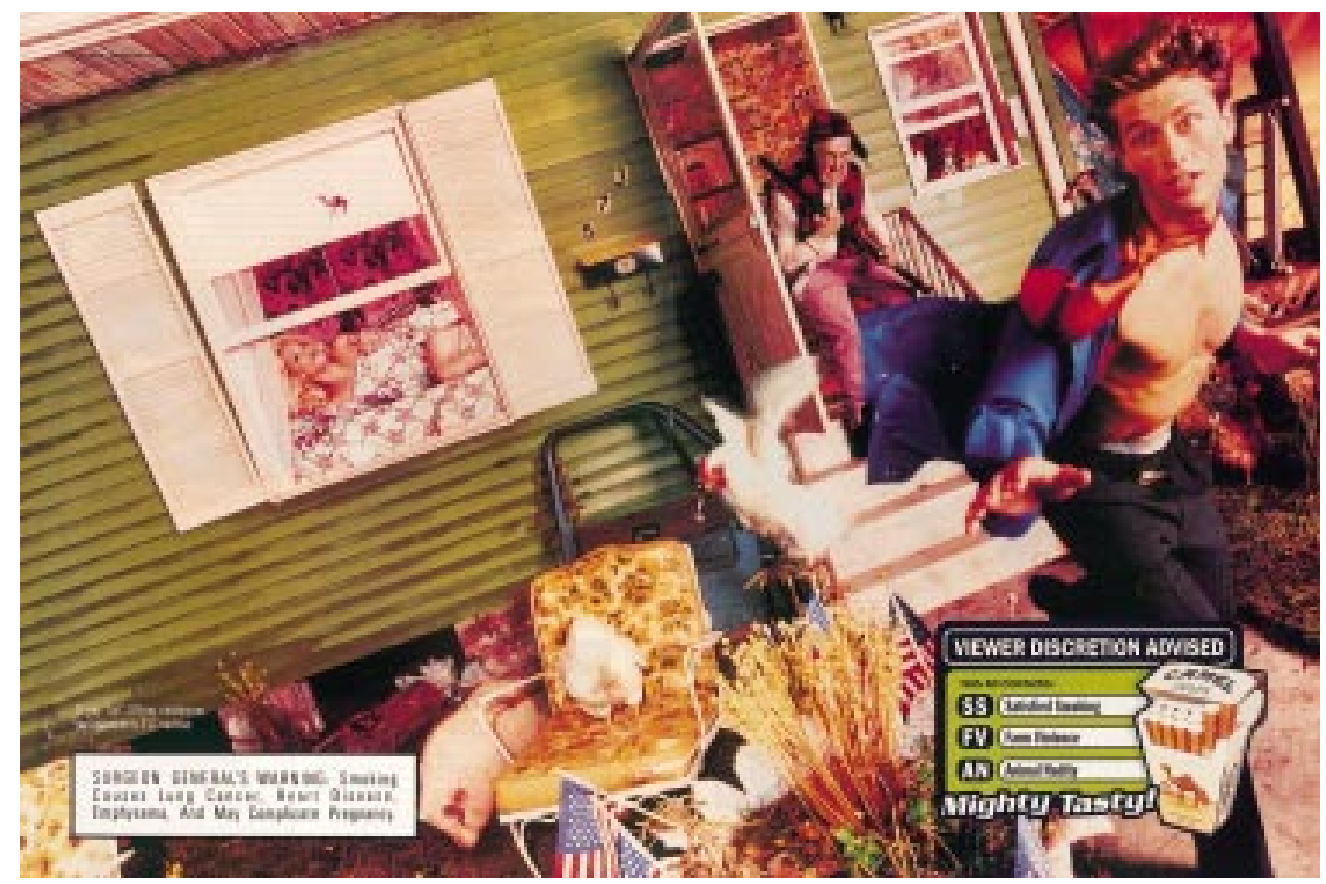

Figure 1 
corner calls attention to: "SS. Satisfied Smoking. FV. Farm Violence. AN. Animal Nudity."

Another ad (figure 2) has the same approach. It depicts the butler and the babe-alicious maid in an aristocratic home conspiratorially defiling the meal with a cigarette ash before serving their mean employers, who are in the opulent dining room callously ringing the service bell.

The scenario plays off the insipid noble poor versus evil rich class-hatred mentality that made Titanic such a hit with teenage girls. But, once again, the ad comments on itself via the warning panel (IR. Idle Rich. ABR. Abusive Bell Ringing. PA. Premeditated Ashing.).

This sort of postmodern self-reference isn't as clever as it thinks it is, nor even all that amusing. What it is, however, is precisely the tack taken by many marketers to appeal to the supposedly media-wise younger generation.

How young?

Very young. For instance, the principal practitioner of this strategy is Sprite [a soft drink].

Meantime, the whole idea of lampooning viewer-discretion advisories seems calculated to ridicule and undercut the whole class of authoritarian warnings such as, um, just to name one: SMOKING CAUSES LUNG CANCER, HEART DISEASE, EMPHYSEMA AND MAY COMPLICATE PREGNANCY.

Hmmm, let's see. Who most responds to attacks on authority? Is it adults? No, not adults. Why-you know what?-it's teenagers! For gosh sakes, it's probably just a coincidence.

It's probably just a coincidence that, after being shamed into retiring Joe Camel, and replacing him with a sophisticated (and quite magnificent) campaign aimed clearly at adults, and watching sales flatten, RJ Reynolds is back with ads using the psychology, sensibilities and iconography of the MTV crowd.

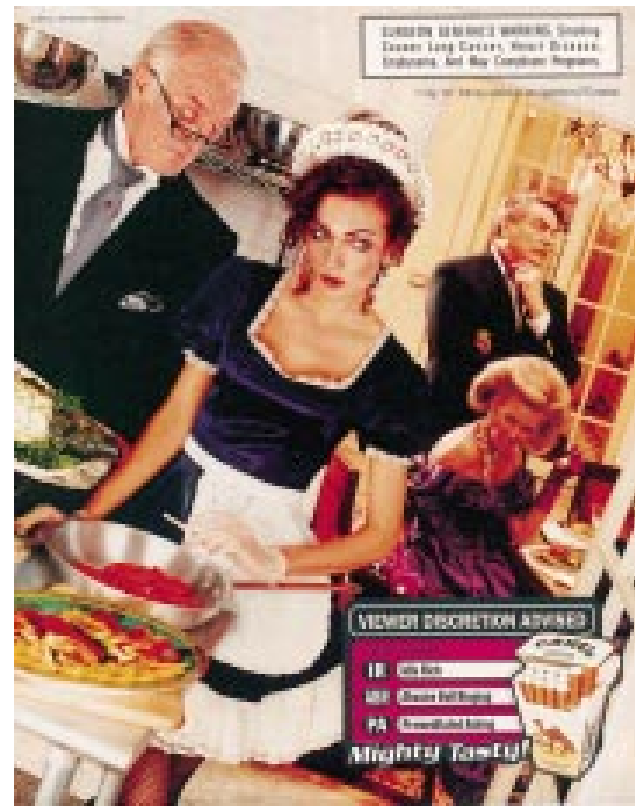

Figure 2

This stuff isn't as nakedly despicable as Joe Camel, who seduced not only teenagers but small children. And it's tempting to give RJR the benefit of the doubt when it argues this campaign is aimed at over-21-year-olds.

But, once again, advertising is a shotgun, not a rifle, and the issue is who unavoidably-or intentionally-will be caught in the spray. Considering the company's history, and these ads' sly assault on protectors of the commonweal, giving RJR the benefit of any doubt would be, shall we say, mighty hasty.

BOB GARFIELD "Advertising Age", 740 North Rush Street, Chicago, Illinois 60611, USA 